\title{
Predicting Pre-emptive Discussions of Biologic Treatment: Results from an Openness and Preference Survey of Inflammatory Bowel Disease Patients and Their Prescribers
}

\author{
M. Furaha Kariburyo · Lin Xie · Amanda Teeple · Haoran Tan • \\ Michael Ingham
}

Received: October 27, 2016/Published online: May 8, 2017

(c) The Author(s) 2017. This article is an open access publication

\begin{abstract}
Introduction: It is important to compare patient and provider discrepancies on stated openness to and preference for biologics as well as predictors associated with initial discussions on biologic use.
\end{abstract}

Methods: Patients $(N=263)$ and physicians $(N=100)$ completed a self-administered Webbased survey assessing demographics, health characteristics, and behaviors related to inflammatory bowel disease (IBD) treatment. Bootstrap methods were used to check discrepancies between providers' and patients' stated openness to and preference for biologics. Classification and regression tree (CART) analysis identified patient-specific predictors associated with initial biologics discussions.

Results: A total of 170 patients responded consistently to preference questions, and 169 patients responded consistently to openness questions. Physicians significantly

Enhanced content To view enhanced content for this article go to http://www.medengine.com/Redeem/ 4B18F06020323076.

M. F. Kariburyo $(\varangle) \cdot$ L. Xie $\cdot$ H. Tan

STATinMED Research, 211 N. 4th Ave., Ste 2B,

Ann Arbor, MI 48104, USA

e-mail: fkariburyo@statinmed.com

A. Teeple $\cdot$ M. Ingham

Janssen Scientific Affairs, LLC, 800 Ridgeview Dr.,

Horsham, PA 19044, USA overestimated patients' openness to biologics in general $(85.46 \%$ vs. $74.61 \%, p<0.0001)$, but underestimated patients' openness to the intravenous (IV) mode of administration (MOA; $55.97 \%$ vs. $63.96 \%, p<0.0001)$. Overall, physicians significantly underestimated patient preference for IV MOA $(22.07 \%$ vs. $42.35 \%$, $p<0.0001)$ and, to a lesser extent, subcutaneous MOA (48.84\% vs. $54.69 \%, p<0.0001)$. Among Crohn's disease $(\mathrm{CD})$ patients $(N=123)$, CART threshold analysis identified an inpatient visit in the last 6 months, CD diagnosis for more than 3 years, and non-adherence to prior IBD treatment as most positively predictive of having an initial biologics discussion.

Conclusion: Physicians appear to underestimate patient preferences in favor of biologics, especially IV formulations. Since it is unclear if physicians were aware of the patients' preferences beforehand, this study supports the need for validated, shared decision-making tools when initiating IBD treatment. Additional studies are necessary to measure physicians' influences on patient preference/treatment-related decisions and the impact on patient outcomes.

Keywords: Classification and regression tree analysis; Crohn's disease; Gastroenterology; Inflammatory bowel disease; Mode of administration; Patient preferences; Ulcerative colitis 


\section{INTRODUCTION}

Inflammatory bowel disease (IBD)_including the two major forms, ulcerative colitis (UC) and Crohn's disease (CD) - is believed to originate from genetic and environmental risk factors, which lead to a chronic systemic inflammatory response primarily manifested in the digestive tract [1]. Northern Europe and North America have observed the highest incidence rates for $\mathrm{UC}$ and $\mathrm{CD}$ [2]. Incidence rates were reported to be 20.2 per 100,000 person-years for UC and 19.2 per 100,000 person-years for CD in North America, with a global increase in recent decades [3]

Traditional treatment focuses on reducing inflammation, which does not improve the inflammatory process [4]. The pro-inflammatory cytokine tumor necrosis factor- $\alpha$ (TNF $\alpha)$ and cell-surface glycoprotein $\alpha 4$ integrins are mediators of inflammation in IBD. Biologic therapies targeting the two mediators were developed to treat IBD patients who failed conventional therapies and are superior to placebos [5].

Since IBD is characterized by exacerbation and remission, higher levels of psychological distress are observed in patients, leading to increased patient-physician discordance [6]. In a study of two national surveys, $62 \%$ of IBD patients reported difficulty living a normal life, compared with $36 \%$ by gastroenterologists' estimation [7]. Perceptions of certain types of risk and benefits for IBD treatment also differ between patients and physicians. It is reported that patients are more willing to accept higher risks from IBD treatment, especially colectomy, than physicians had perceived on their behalf [8]. However, concerns regarding adverse events-such as progressive multifocal leukoencephalopathy-may impede patients seeking medication and result in poorly controlled disease.

It is believed that communication between physicians and patients regarding the risks of IBD treatment plays an important role in the decision-making process [9]. Long-term meta-analysis showed that patient communication with physicians improved their medication adherence by $19 \%$, and was positively associated with health outcomes $[10,11]$. Models were also developed to assist shared treatment decision-making between physicians and patients [12]. Moreover, research found that patients tended to rate these discussions more favorably than their physicians, which indicates that patients believe there is a need to exchange information with medical experts [13]. Biologic therapy is a relatively new treatment for IBD which may lead to patients knowing less about biologic treatment than physicians do. Therefore, more shared decision-making discussions between patients and physicians may be needed to make an informed decision regarding transferring to this new treatment.

This current study stemmed from a prior study including rheumatoid arthritis patients, which suggested that more biologic-naïve patients were open to subcutaneous (SQ) and intravenous (IV) biologic therapy and may show greater preference to IV biologic therapy than physicians previously believed [14]. The study findings of the rheumatoid arthritis research suggested that while physicians and biologic-naïve patients appear to generally agree in terms of openness to biologic treatment, discrepancies still exist in the perception of openness and preference to a specific mode of administration (MOA).

Apart from the study of discrepancies between patients and physicians, factors influencing UC or CD patient preference for treatment with biologics were also assessed in our study. Understanding the differences in patient and physician perspectives of biologic treatment preferences may prompt more informed, shared decisions among patients and prescribers.

The aim of the secondary analysis was to provide additional bivariate and multivariate analyses of the survey results from UC and CD (IBD) patients who were treated with a disease-modifying antirheumatic drug (DMARD) including methotrexate, hydroxychloroquine, sulfasalazine, and leflunomide-but not yet prescribed biologic therapy. The study aimed to assess openness to and preference for biologic 
therapy, to describe discrepancies on stated openness to and preference for biologics between patients and providers, and to identify patient-specific predictors associated with having a discussion with a physician about biologics. Patient-specific factors based on those who had discussed biologic treatment with their gastroenterologist were considered latent predictive surrogates for patients more likely to advance to actual biologic treatment.

\section{METHODS}

\section{Patients, Providers, and Study Design}

This article is based on previously conducted studies [14] and does not involve any new studies of human or animal subjects performed by any of the authors. This study was approved by Sterling IRB as an expedited review.

This was a retrospective study using survey data from a prior double-arm study that included both patient preference and prescriber-perceived patient preference. Adult UC or CD patients (at least 18 years) who received DMARD therapy but no biologic therapy, and a cohort of gastroenterologists were invited to complete a self-administered, Web-based survey assessing demographics, health characteristics, and behaviors related to IBD treatment. Patients were identified through the Sample Czar non-profit-focused panel or All Global online consumer panel. Patients that responded consistently, with non-contradictory responses, were included in this analysis. Health care providers recruited for this study were board-certified gastroenterologists with 3-30 years of medical practice experience, spent at least 50\% of their time in a clinical setting, saw at least 50 IBD patients per month, and had no pharmaceutical or governmental conflicts of interest. Health care providers recruited for this study had no pharmaceutical or governmental conflicts of interest. Physicians with clinical trial experience were not excluded or consider that a conflict of interest.

Patients who fulfilled the inclusion criteria were further stratified as those who already had versus did not yet have a discussion with their gastroenterologist regarding treatment with biologics. Patients' sociodemographic, economic, and clinical characteristics were reported, including age, sex, race/ethnicity, employment status, annual household income, years since IBD diagnosis, site of care, IBD medications, out-of-pocket costs for UC or CD medications, all-cause health care utilization in the past 6 months, attitudes toward biologics, treatment satisfaction (Treatment Satisfaction Questionnaire for Medication [TSQM-v2]), and treatment adherence (Morisky Medication Adherence Scale [MMAS-8]). The Charlson comorbidity index score, a weighted summation of 23 comorbid conditions and warfarin use, was also calculated [15-17].

\section{Outcomes and Assessments}

The survey included questions related to patient openness, biologics, and specific MOA (IV or SQ). The responses were structured to a 5-point Likert scale ranging from 1 (not at all open) to 5 (extremely open). In this study, participants were considered open to a biologic or MOA if their answers were "Very open" or "Extremely open," neutral if answers included "Somewhat open," and not open if they answered "Not at all open" or "Not very open."

The survey also posed questions related to the preference of a biologic MOA. The answers were "Strongly prefer IV," "Somewhat prefer IV," "No preference between IV and SQ," "Somewhat prefer SQ," and "Strongly prefer SQ." Those who responded "Strongly prefer IV" or "Somewhat prefer IV" were regarded as participants who preferred IV MOA. Those who responded "Somewhat prefer SQ" or "Strongly prefer SQ" were regarded as participants who preferred SQ MOA.

\section{Statistical Methods}

Descriptive analyses were performed for comparisons of all patient characteristics. Percentages were provided for dichotomous and polychotomous variables. Means were calculated for continuous variables. Student $t$ tests were used to examine differences in continuous 
variables of interest between patients who had a discussion versus those who did not. Chi-square tests of proportion were used to examine bivariate associations for categorical variables. Standardized differences (SDs), defined as the absolute difference in sample means divided by an estimate of the pooled SD of each variable, were provided. The SDs help to distinguish practical (i.e., clinical) from statistical significance. To allow for easy interpretation, SDs were reported as 100 times the absolute value of the actual SDs. Any SD greater than 20 was considered significant [18].

To compare physician responses about their patients versus individual patient responses, population samples for both were derived using bootstrapping statistical techniques, where responses were randomly oversampled 10,000 times with replacement. Physicians' perceptions of their patient populations were compared in a stratified analysis of responses from patients who had a biologic discussion versus those who did not. Student $t$ tests were used to calculate $p$ values.

Classification and regression tree (CART) analysis was used to identify patient-specific predictors associated with having a biologics discussion with a physician. CART is based on binary recursive partitioning of the data and was employed to determine the importance of each variable, starting with all patients and thereafter all newly defined subgroups. At each step of the analysis, the threshold of each variable that yielded the most significant division into two subgroups of patients determined the most likely differentiation between those who had a conversation about biologic treatment versus those who did not. The cross-validation technique was used to prune and optimize the regression tree. CART analysis was conducted among CD patients and all patients separately. All statistical analyses were conducted in SAS version 9.3.

\section{RESULTS}

\section{Patient Characteristics}

A total of 170 patients responded consistently to preference questions, 169 patients responded consistently to openness questions, and 96 patients were assigned to the consistent openness and consistent preference populations. Compared to patients who had a biologic discussion with their physicians, those who did not have a discussion were more likely to be older, white, female, currently taking 5-aminosalacylic acid (5-ASA) therapy to treat UC or CD, worked part-time, and earned less than US $\$ 75,000$ annually. Most patients who did not have a biologic discussion with their physician indicated that they were not aware of different MOAs to treat UC or CD. Compared to patients who did not have a discussion, those who had a biologic discussion had low adherence and were not satisfied with their current DMARD medications (Table 1).

\section{Outcome Assessment}

\section{Bootstrap Analysis}

Openness In general, physicians significantly overestimated patients' openness to biologics (85.46\% vs. $74.61 \%, p<0.0001)$, but underestimated patients' openness to IV MOA $(55.97 \%$ vs. $63.96 \%$ ). Patients who did not have a treatment discussion $(N=70)$ showed less openness to biologics $(52.86 \%)$ compared to patients who had a biologics discussion $(N=99)(89.90 \%)$. The greatest discrepancy among patients who had a discussion was openness to IV MOA between patients and physicians $(75.73 \%$ and $55.97 \%$, respectively). Patients who did not have a discussion were less open to biologics IV MOA (47.14\%) and SQ MOA (45.72\%) than the physicians' perceived patient responses (55.97\% and 67.98\%, respectively) (Fig. 1).

Preference Overall, physicians significantly underestimated patients' preference for IV MOA ( $22.07 \%$ vs. $42.35 \% ; p<0.0001)$ and, to a lesser extent, SQ MOA $(48.84 \%$ vs. $54.69 \%$; $p<0.0001)$. Patients who had a discussion about biologics with their physician $(N=83)$ were more likely to prefer SQ MOA $(59.04 \%$ vs. $50.51 \%)$ over IV MOA (39.75\% vs. $44.88 \%$ ) compared to patients who did not have a discussion $(N=87)$. Patients with an IBD treatment discussion reported greater preference for 
Table 1 Characteristics of patients diagnosed with UC or CD

\begin{tabular}{|c|c|c|c|c|c|c|}
\hline & \multicolumn{3}{|c|}{$\begin{array}{l}\text { Consistent openness patients } \\
(N=169)\end{array}$} & \multicolumn{3}{|c|}{$\begin{array}{l}\text { Consistent preference patients } \\
(N=170)\end{array}$} \\
\hline & \multirow{2}{*}{$\begin{array}{l}\text { Patients without } \\
\text { a discussion } \\
(N=70) \\
\text { Mean/\% }\end{array}$} & \multicolumn{2}{|c|}{$\begin{array}{l}\text { Patients with } \\
\text { a discussion } \\
(N=99)\end{array}$} & \multirow{2}{*}{$\begin{array}{l}\text { Patients without } \\
\text { a discussion } \\
(N=87) \\
\text { Mean/\% }\end{array}$} & \multicolumn{2}{|c|}{$\begin{array}{l}\text { Patients with } \\
\text { a discussion } \\
(N=83)\end{array}$} \\
\hline & & Mean/\% & SD & & $\overline{\text { Mean/\% }}$ & SD \\
\hline Patient sourced from SSI panel (\%) & 47.1 & 53.5 & -12.7 & 41.4 & 44.6 & -6.4 \\
\hline Patient sourced from Czar panel (\%) & 52.9 & 46.5 & 12.7 & 58.6 & 55.4 & 6.4 \\
\hline $\begin{array}{l}\text { Patients diagnosed with ulcerative colitis } \\
\quad(\%)\end{array}$ & 45.7 & $63.6^{\mathrm{a}}$ & -36.4 & 29.9 & $53.0^{\mathrm{b}}$ & -48.0 \\
\hline $\begin{array}{l}\text { Patients diagnosed with Crohn's disease } \\
\text { (\%) }\end{array}$ & 54.3 & $36.4^{\mathrm{a}}$ & 36.4 & 70.1 & $47.0^{\mathrm{b}}$ & 48.0 \\
\hline Age (mean) & 48.9 & $42.3^{\mathrm{b}}$ & 47.7 & 50.0 & $42.1^{\mathrm{b}}$ & 59.9 \\
\hline Age $18-39(\%)$ & 27.1 & $48.5^{\mathrm{b}}$ & -44.9 & 20.7 & $48.2^{\mathrm{b}}$ & -60.1 \\
\hline Age $40-49(\%)$ & 22.9 & 16.2 & 16.9 & 25.3 & 15.7 & 23.9 \\
\hline Age 50-64 (\%) & 35.7 & 28.3 & 15.9 & 42.5 & 30.1 & 25.9 \\
\hline Age $65+(\%)$ & 14.3 & 7.1 & 23.4 & 11.5 & 6.0 & 19.3 \\
\hline \multicolumn{7}{|l|}{ Sex $(\%)$} \\
\hline Female & 64.3 & 52.5 & 23.9 & 69.0 & 65.1 & 8.3 \\
\hline \multicolumn{7}{|l|}{ Race (\%) } \\
\hline White & 91.4 & $76.8^{\mathrm{a}}$ & 40.7 & 93.1 & $80.7^{\mathrm{a}}$ & 37.1 \\
\hline Black & 2.9 & 9.1 & -26.4 & 1.2 & 6.0 & -26.3 \\
\hline African American & 0.0 & 1.0 & -14.2 & 1.2 & 2.4 & -9.5 \\
\hline Asian or Pacific Islander & 2.9 & 5.1 & -11.2 & 3.5 & 4.8 & -6.9 \\
\hline Other/declined to answer & 2.9 & 8.1 & -23.0 & 1.2 & 6.0 & -26.3 \\
\hline \multicolumn{7}{|l|}{ Ethnicity (\%) } \\
\hline American White (majority) & 87.1 & $65.7^{\mathrm{b}}$ & 52.0 & 92.0 & $75.9^{\mathrm{b}}$ & 44.5 \\
\hline Minority & 12.9 & $33.3^{\mathrm{b}}$ & -49.8 & 8.1 & $24.1^{\mathrm{b}}$ & -44.5 \\
\hline Undetermined & 0.0 & 1.0 & -14.2 & 0.0 & 0.0 & 0.0 \\
\hline \multicolumn{7}{|l|}{ Annual household income (\%) } \\
\hline$<\mathrm{US} \$ 25,000$ & 4.3 & 10.1 & -22.5 & 6.9 & 12.1 & -17.6 \\
\hline US $\$ 25,000-34,999$ & 11.4 & 8.1 & 11.2 & 8.1 & 12.1 & -13.3 \\
\hline US $\$ 35,000-49,999$ & 21.4 & $10.1^{a}$ & 31.3 & 16.1 & 8.4 & 23.4 \\
\hline US\$50,000-74,999 & 30.0 & 21.2 & 20.1 & 32.2 & 19.3 & 29.7 \\
\hline US\$75,000-150,000+ & 28.6 & $46.5^{\mathrm{a}}$ & -37.4 & 29.9 & $47.0^{a}$ & -35.5 \\
\hline
\end{tabular}


Table 1 continued

\begin{tabular}{|c|c|c|c|c|c|c|}
\hline & \multicolumn{3}{|c|}{$\begin{array}{l}\text { Consistent openness patients } \\
(N=169)\end{array}$} & \multicolumn{3}{|c|}{$\begin{array}{l}\text { Consistent preference patients } \\
(N=170)\end{array}$} \\
\hline & \multirow{2}{*}{$\begin{array}{l}\text { Patients without } \\
\text { a discussion } \\
(N=70) \\
\text { Mean } / \%\end{array}$} & \multicolumn{2}{|c|}{$\begin{array}{l}\text { Patients with } \\
\text { a discussion } \\
(N=99)\end{array}$} & \multirow{2}{*}{$\begin{array}{l}\text { Patients without } \\
\text { a discussion } \\
(N=87) \\
\text { Mean/\% }\end{array}$} & \multicolumn{2}{|c|}{$\begin{array}{l}\text { Patients with } \\
\text { a discussion } \\
(N=83)\end{array}$} \\
\hline & & Mean/\% & SD & & Mean/\% & SD \\
\hline Declined to answer & 4.3 & 4.0 & 1.2 & 6.9 & 1.2 & 29.0 \\
\hline \multicolumn{7}{|l|}{ Employment status (\%) } \\
\hline Full-time & 44.3 & $63.6^{\mathrm{a}}$ & -39.3 & 48.3 & 61.5 & -26.5 \\
\hline Part-time & 11.4 & 7.1 & 15.0 & 12.6 & 7.2 & 18.1 \\
\hline Self-employed & 2.9 & 5.1 & -11.2 & 2.3 & 6.0 & -18.6 \\
\hline Homemaker & 15.7 & $2.0^{\mathrm{b}}$ & 49.3 & 10.3 & $1.2^{\mathrm{a}}$ & 39.7 \\
\hline Retired & 18.6 & 9.1 & 27.6 & 17.2 & 9.6 & 22.3 \\
\hline Unemployed & 2.9 & 0.0 & 24.1 & 2.3 & 2.4 & -0.7 \\
\hline On long-term disability & 5.7 & 9.1 & -12.9 & 5.8 & 8.4 & -10.4 \\
\hline Student & 5.7 & 7.1 & -5.5 & $5.8 \%$ & 7.2 & -6.0 \\
\hline \multicolumn{7}{|l|}{ Clinical characteristics } \\
\hline Years since IBD diagnosis (mean) & 12.2 & 9.5 & 24.2 & 13.3 & $9.1^{\mathrm{a}}$ & 38.0 \\
\hline Charlson comorbidity index (mean) & 0.2 & 0.4 & -20.9 & 0.2 & 0.2 & -3.1 \\
\hline \multicolumn{7}{|l|}{ IBD medications (\%) } \\
\hline $\begin{array}{l}\text { 5-ASAs currently taken to treat UC or } \\
\text { CD }\end{array}$ & 80.0 & $63.6^{\mathrm{a}}$ & 36.8 & 82.8 & $68.7^{\mathrm{a}}$ & 33.1 \\
\hline $\begin{array}{l}\text { Immunomodulators currently taken to } \\
\text { treat } \mathrm{UC} \text { or } \mathrm{CD}\end{array}$ & 28.6 & $56.6^{\mathrm{b}}$ & -58.7 & 27.6 & $55.4^{\mathrm{b}}$ & -58.5 \\
\hline $\begin{array}{l}\text { Steroids currently taken to treat } \mathrm{UC} \text { or } \\
\mathrm{CD}\end{array}$ & 4.3 & $17.2^{\mathrm{a}}$ & -42.3 & 10.3 & 13.3 & -9.0 \\
\hline $\begin{array}{l}\text { Antibiotics currently taken to treat } \mathrm{UC} \\
\text { or } \mathrm{CD}\end{array}$ & 2.9 & 7.1 & -19.4 & 2.3 & 6.0 & -18.6 \\
\hline \multicolumn{7}{|c|}{ All-cause health care utilization (past 6 months) (mean) } \\
\hline $\begin{array}{l}\text { ER visits, hospital stays, and/or times } \\
\text { seen physician for UC/CD in past } \\
6 \text { months }\end{array}$ & 4.2 & $7.1^{\mathrm{b}}$ & -54.4 & 4.1 & $6.6^{\mathrm{b}}$ & -43.2 \\
\hline \multicolumn{7}{|l|}{ Additional patient characteristics (\%) } \\
\hline Patient aware of infusion for treatment & 37.1 & $70.7^{\mathrm{c}}$ & -71.1 & 43.7 & $63.9^{\mathrm{b}}$ & -41.1 \\
\hline $\begin{array}{l}\text { Patient aware of self-injection for } \\
\text { treatment }\end{array}$ & 51.4 & $84.9^{\mathrm{c}}$ & -76.3 & 54.0 & $78.3^{\mathrm{b}}$ & -52.8 \\
\hline
\end{tabular}


Table 1 continued

\begin{tabular}{|c|c|c|c|c|c|c|}
\hline & \multicolumn{3}{|c|}{$\begin{array}{l}\text { Consistent openness patients } \\
(N=169)\end{array}$} & \multicolumn{3}{|c|}{$\begin{array}{l}\text { Consistent preference patients } \\
(N=170)\end{array}$} \\
\hline & \multirow{2}{*}{$\begin{array}{l}\text { Patients without } \\
\text { a discussion } \\
(N=70) \\
\text { Mean/\% }\end{array}$} & \multicolumn{2}{|c|}{$\begin{array}{l}\text { Patients with } \\
\text { a discussion } \\
(N=99)\end{array}$} & \multirow{2}{*}{$\begin{array}{l}\text { Patients without } \\
\text { a discussion } \\
(N=87) \\
\text { Mean/\% }\end{array}$} & \multicolumn{2}{|c|}{$\begin{array}{l}\text { Patients with } \\
\text { a discussion } \\
(N=83)\end{array}$} \\
\hline & & Mean/\% & SD & & Mean/\% & SD \\
\hline $\begin{array}{l}\text { Physician advice very-extremely } \\
\text { influential }\end{array}$ & 84.3 & 85.9 & -4.4 & 86.2 & 88.0 & -5.2 \\
\hline $\begin{array}{l}\text { Physician recommended one of the } \\
\text { biologics }\end{array}$ & 0.0 & $54.6^{c}$ & -154.1 & 0.0 & $51.8^{\mathrm{c}}$ & -145.7 \\
\hline Ever/currently intravenously infused & 1.4 & $18.2^{\mathrm{b}}$ & -58.4 & 1.2 & $14.5^{\mathrm{b}}$ & -50.9 \\
\hline Ever/currently received self-injectable & 0.0 & $21.2^{\mathrm{c}}$ & -73.0 & 1.2 & $15.7^{\mathrm{b}}$ & -53.9 \\
\hline $\begin{array}{l}\text { Signs or symptoms currently } \\
\text { experiencing }\end{array}$ & 68.6 & $91.9^{c}$ & -60.9 & 75.9 & $92.8^{\mathrm{b}}$ & -47.5 \\
\hline \multicolumn{7}{|l|}{ Attitudes towards biologics } \\
\hline \multicolumn{7}{|c|}{ I will strongly consider biologic treatment only at the point when my daily activities are impacted (\%) } \\
\hline Disagree & 17.1 & 13.1 & 11.1 & 5.8 & 12.1 & -22.1 \\
\hline Neither agree nor disagree & 32.9 & 23.2 & 21.4 & 36.8 & 26.5 & 22.1 \\
\hline Agree & 50.0 & 63.6 & -27.6 & 57.5 & 61.5 & -8.1 \\
\hline \multicolumn{7}{|l|}{ Global satisfaction (\%) } \\
\hline Satisfied & 80.0 & $63.6^{\mathrm{a}}$ & 36.8 & 74.7 & $60.2^{\mathrm{a}}$ & 31.1 \\
\hline $\begin{array}{l}\text { Between satisfaction and } \\
\text { dissatisfaction }\end{array}$ & 15.7 & 22.2 & -16.6 & 21.8 & 22.9 & -2.5 \\
\hline Not satisfied & 4.3 & $14.1^{\mathrm{a}}$ & -34.4 & 3.5 & $16.9^{\mathrm{b}}$ & -45.3 \\
\hline \multicolumn{7}{|l|}{ Adherence (\%) } \\
\hline High adherence $(0)$ & 32.9 & $18.2^{\mathrm{a}}$ & 33.9 & 23.0 & 18.1 & 12.1 \\
\hline Medium adherence (1-2) & 21.4 & 27.3 & -13.6 & 26.4 & 18.1 & 20.1 \\
\hline Low adherence (3-8) & 45.7 & 54.6 & -17.6 & 50.6 & 63.9 & -26.9 \\
\hline
\end{tabular}

Standardized difference is defined as the difference in sample means or proportions divided by standard error; reported as $100 \times \mid$ actual standardized difference $\mid$. Standardized differences $>|20|$ are considered significant. A positive value indicates higher means or proportion in the "Patients without a discussion" versus "Patients with a discussion")

$C D$ Crohn's disease, IBD inflammatory bowel disease, SD standardized difference, SSI Survey Sampling International, UC ulcerative colitis

${ }^{a} p$ value $<0.05$

b $p$ value $<0.01$

c $p$ value $<0.0001$ 


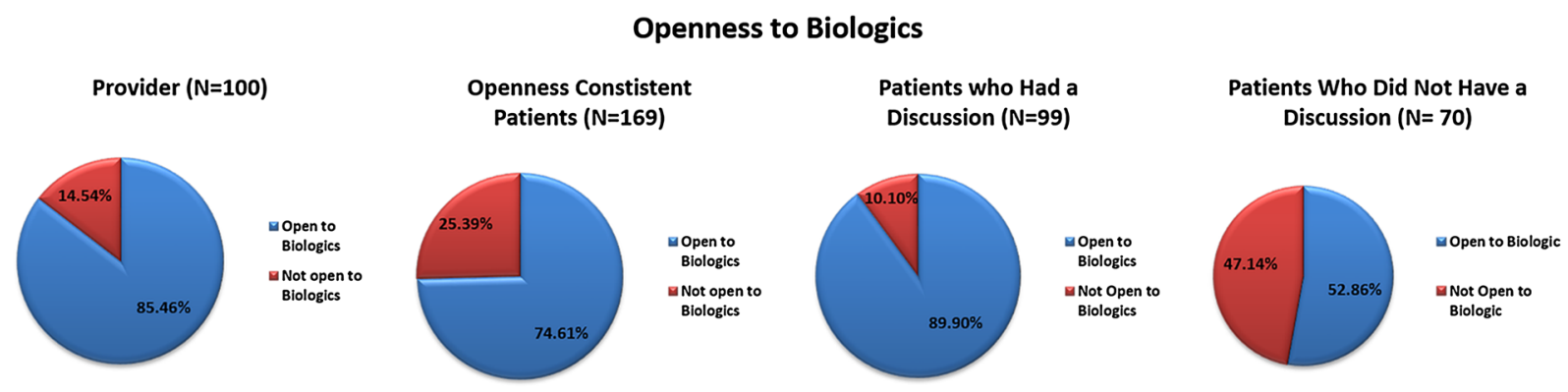

\section{Openness to IV}
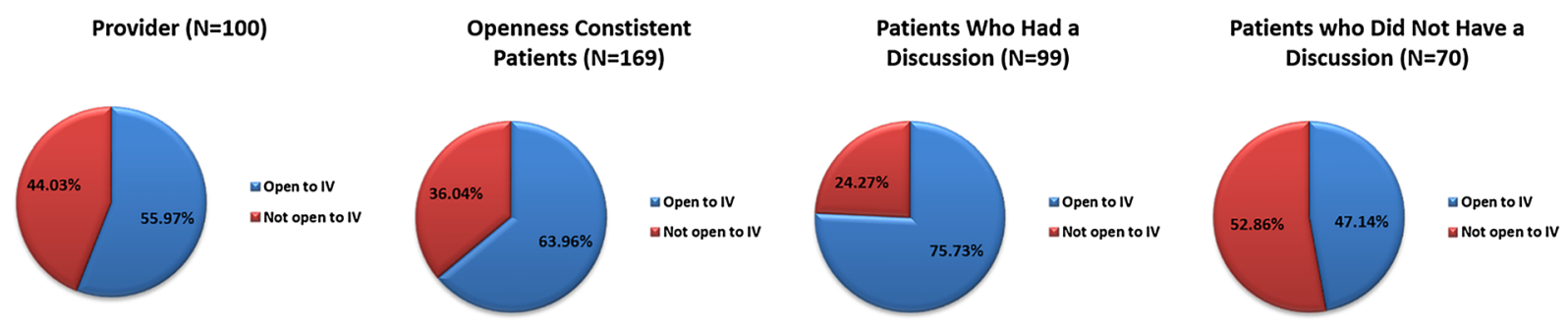

Openness to SQ
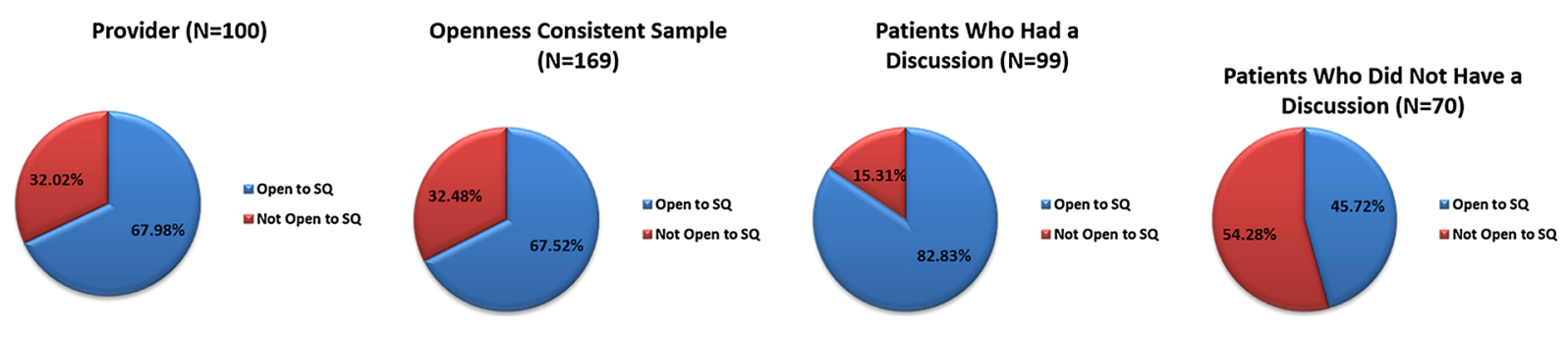

Fig. 1 Bootstrap analysis: consistent openness sample. Patients who had a discussion showed greater openness to IV and SQ biologics compared to both the all-consistent response patients and physician-perceived patient response

IV (39.75\%) and SQ (59.04\%) compared to physician responses $(22.07 \%$ and $48.84 \%$, respectively) (Fig. 2).

\section{CART Analysis}

The results of our study showed that a small percentage of CD patients had discussions with their physicians about biologic treatment: a total of 46 out of 123 patients with CD reported having a biologics discussion with their gastroenterologist. After considering all primary and surrogate splits, 10 variables of importance were chosen by CART based on improvement scores, including frequency of resource use, symptoms, number of symptoms, number of years since diagnosis and treatment duration, satisfaction with current treatment, and adherence levels. CART threshold analysis identified at least one hospitalization in the last 6 months as the most important predictor of having a discussion about initiating biologic treatment. If not hospitalized in the last 6 months, patients were most likely to have a discussion regarding biologics if they were treated with mesalamine for less than 53 months, were less than extremely satisfied with the current treatment, and had a diagnosis for more than 3 years. If there was at most 3 years since diagnosis, those with less than full adherence were the most predictive (Fig. 3).

CART analysis was also conducted in the overall population $(N=263)$. A total of 131 

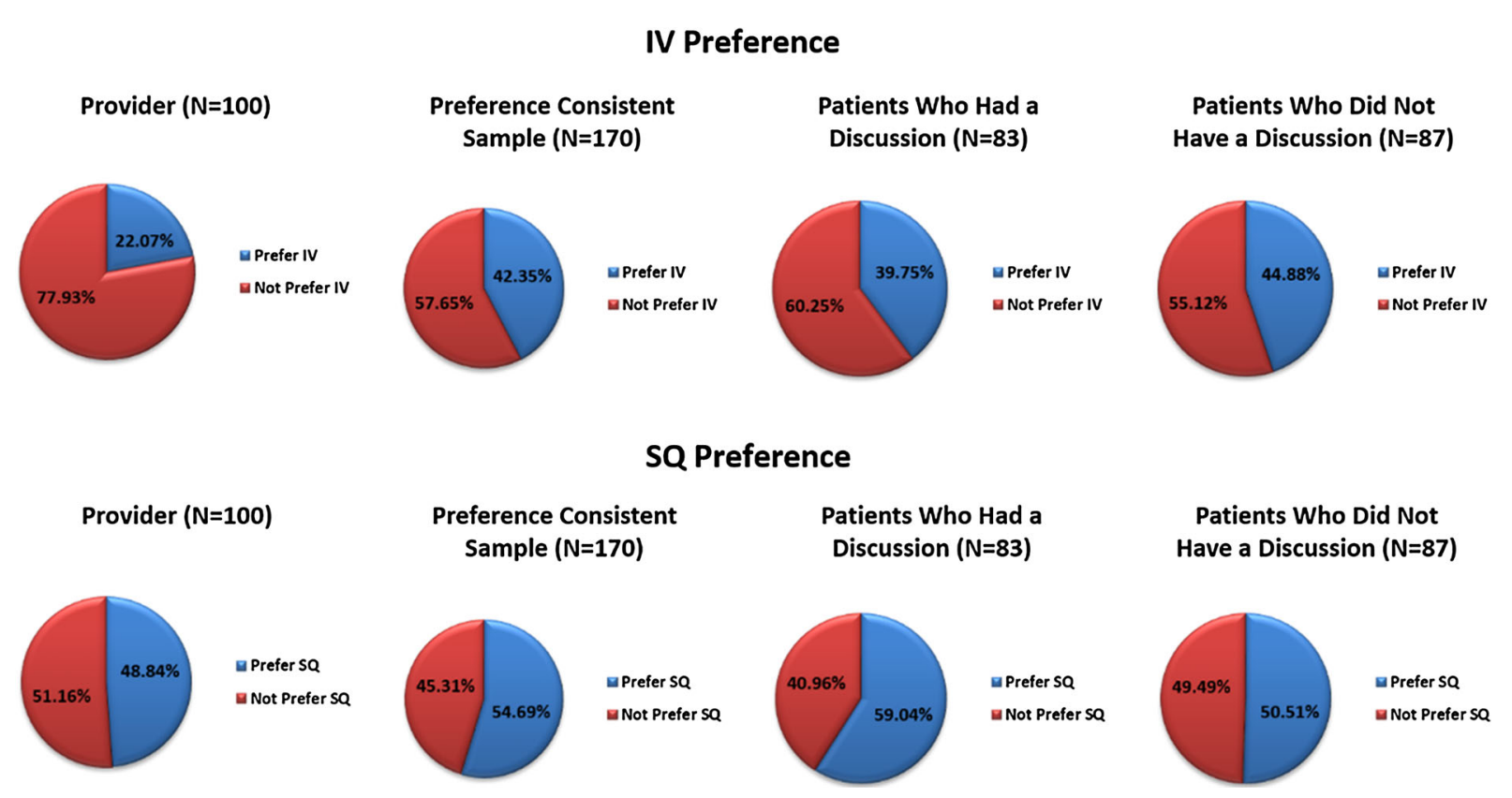

Fig. 2 Bootstrap analysis: consistent preference sample. Patients who had a discussion showed greater preference for SQ but less preference for IV compared to patients that did not have a discussion

patients reported a discussion with their gastroenterologist about starting a biologic. In the general population, CART computed 13 variables that were of importance after considering all primary and surrogate splits. These variables included number of resources used, number of symptoms, number of years since diagnosis, and treatment duration. CART threshold analysis identified at least one hospitalization in the last 6 months as the most important predictor of having a discussion with a physician. If not hospitalized in the last 6 months, the most predictive patients had 3-6 office visits in the last 6 months, mesalamine treatments for less than 74 months, Lialda treatments specifically for less than 8.5 months, and an IBD diagnosis less than 30 years ago (Fig. 4).

\section{DISCUSSION}

Previous research suggested that a greater number of biologic-naïve rheumatology patients were open to both SQ and IV biologic therapy-and may prefer IV biologic therapycompared to rheumatologists' perceptions of patient beliefs [14]. This retrospective study using data from the prior study's double-arm survey described discrepancies on stated openness to and preference for biologics between patients and providers and identified patient-specific predictors associated with having a biologics discussion with a physician. The current research was intended to test whether a similar discrepancy exists between gastroenterologists and patients with CD or UC.

The results suggest that while physicians and biologic-naïve patients appear to be aligned in terms of openness to biologic treatment, there is a discrepancy in perceived openness to specific MOAs. The differences in perceived openness and preference between prescribers and patients may be because treatment for IBD has become more complex as new medications were introduced and treatment algorithms have evolved [19]. Patients' values and preferences vary widely. In the era of multiple treatment options for a particular disease, patients will agree on what is right for them on the basis of how they value benefits versus harms [20]. Patients' choice of treatment will often depend on disease severity, tolerance of symptoms, confidence for response, and-more importantly- 


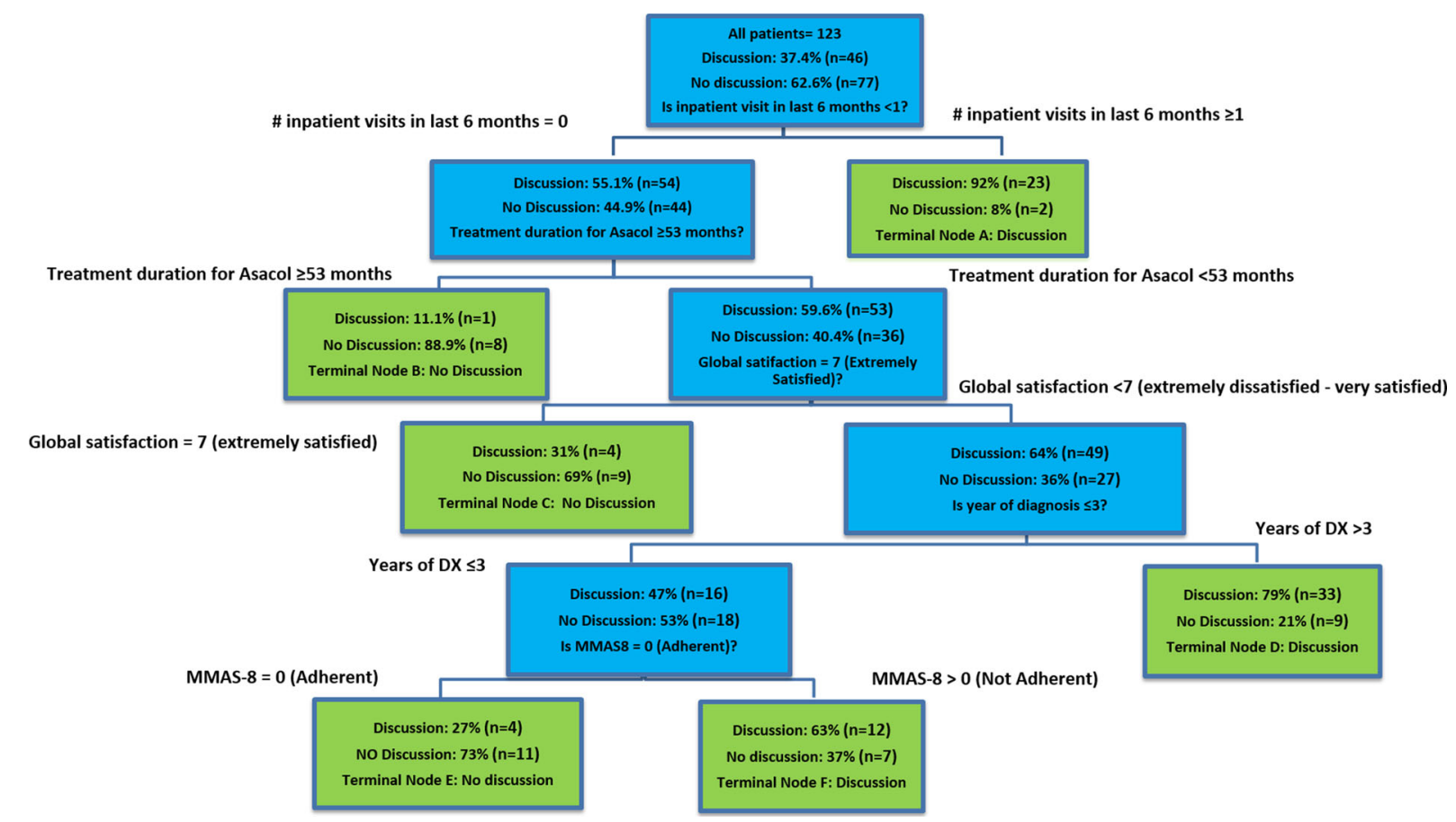

Fig. 3 CART analysis: optimal tree for Crohn's disease patients. CART threshold analysis identified at least one hospitalization in the last 6 months as the most important predictor. If not hospitalized in the last 6 months, the most predictive patients had mesalamine treatments for less than 53 months, less than extreme satisfaction with current treatment, and a diagnosis for more than

on what they know from family, friends, doctors, and advertising [21].

The discrepancy between perceived openness and preference supports the need for a discussion before IBD patients initiate biologics, as this will provide opportunities for more informed, shared decision-making between patients and prescribers when initiating new IBD treatment. Shared decision-making models suggest that physicians have the responsibility to inform and recommend treatment options to patients, but the decision on how to proceed is shared $[19,22]$. In this study, the majority of patients who did not have a biologic discussion with their physicians were not aware of different MOAs to treat UC or CD. Although not all patients may want to participate in shared decision-making [23], the majority will want to participate in this process. This is particularly true if the outcomes are significant, such as
3 years. If there was at most 3 years since diagnosis, those with less than full adherence were most predictive. Blue boxes internal nodes which are non-terminal nodes with splitting rules; Green boxes leaf nodes which are terminal nodes. This implies that after the split, further splitting of the data does not explain enough of the variance to be relevant in describing the outcome

anti-TNF or cyclosporine treatment versus surgery for UC [20].

Results from the bootstrap analysis showed that a discussion with a physician may lead to greater openness and preference to starting a biologic and a specific MOA. Patient-specific factors for those discussing biologic treatment were considered latent predictive surrogates for patients who were more likely to move to actual biologic treatment. CART analysis was performed to identify patient-specific factors associated with having a biologic discussion. Findings indicated that among many patient-specific factors, the most positive predictor of having a biologics discussion with a physician for patients with $\mathrm{CD}$ was having an inpatient visit in the last 6 months, a diagnosis of $\mathrm{CD}$ for more than 3 years, and non-adherence to prior IBD treatment. Among IBD patients, CART threshold analysis identified at 


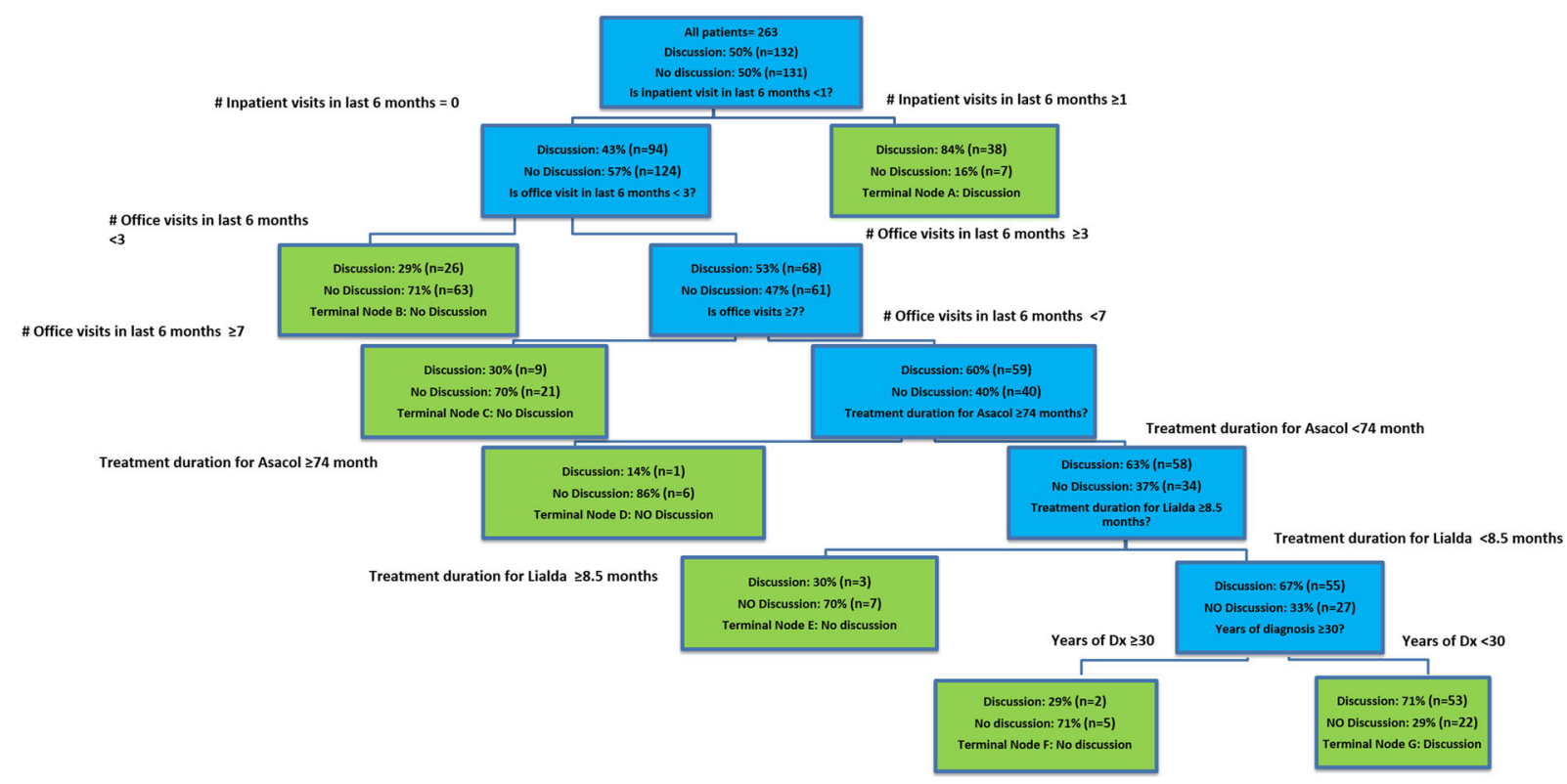

Fig. 4 CART analysis: optimal tree for all patients. CART threshold analysis identified at least one hospitalization in the last 6 months as the most important predictor. If not hospitalized in the last 6 months, the most predictive patients had at least three office visits and less than seven office visits in the last 6 months, mesalamine treatments for less than 74 months, Lialda

least one hospitalization in the last 6 months and an IBD diagnosis for less than 30 years as the most important predictors of having a discussion about initiating biologic treatment.

This study also included patients with consistent openness or preference answers to the survey. Among 263 patients, 169 gave consistent answers regarding openness, and 170 gave consistent answers on preference of biologic therapy to treat IBD. These populations were also stratified as patients who already had a biologics discussion versus those who had not. Sociodemographic, economic, and clinical characteristics were similar between these populations. Although study patients were biologic-naïve, their treatment openness or preference of MOA may have been influenced by personal attitudes towards safety and convenience with current or previous IBD treatments, treatment experience, and perception of current disease status. On the basis of the survey questions, we were unable to confirm who initiated conversations among those with a treatments for less than 8.5 months, and an IBD diagnosis more than 30 years ago. Blue boxes internal nodes which are non-terminal nodes with splitting rules; Green boxes leaf nodes which are terminal nodes. This implies that after the split, further splitting of the data does not explain enough of the variance to be relevant in describing the outcome

biologics treatment conversation, the contents of the information presented to patients, whether the information was consistent across physicians, or those who already had a discussion. Additionally, patients surveyed were not necessarily patients of the physicians surveyed in the current analysis.

The data from this survey study aids in the understanding of the potential role prescribers play in providing comprehensive education regarding UC or CD treatment options, eliciting concerns about medications, and ascertaining that patients possess an accurate and clear understanding of treatment risks and benefits. However, certain limitations should be acknowledged. This was an observational study, and causality between the instance of a biologic treatment conversation and biologic treatment initiation could not be established, as not all patients who had a discussion with their physician initiated biologic therapy. Because patient and prescriber reports were sourced from a self-administered, Web-based 
questionnaire, and patients self-reported their disease diagnosis, this small sample of participants may not be generalizable to the overall global IBD patient and gastroenterologist populations. However, to our knowledge, this is the largest survey conducted to date evaluating openness to and preference for biologic therapy in the treatment of IBD.

\section{CONCLUSION}

This retrospective analysis of IBD patients' and prescribers' openness and preferences suggested that physicians appear to underestimate patient preferences in favor of biologics, especially IV formulations. Since it is unclear if physicians were aware of the patients' preferences beforehand, this study supports the need for validated, shared decision-making tools when initiating IBD treatment. Although discussions with physicians appear to raise patients' comfort level towards biologics and specific MOAs, it appears that a small percentage of patients already had discussions as part of their current treatment plan. There is also a need for additional studies to measure physicians' influences on patient preference/treatment-related decisions and the impact on patient outcomes.

The key findings provided by CART analysis conclude that among many patient-specific factors, having an inpatient visit in the last 6 months, having been diagnosed with CD for more than 3 years, and non-adherence prior to IBD treatment are predictive of having a discussion with a physician about biologics. This suggests that these patients are more likely to move to a biologic treatment.

\section{ACKNOWLEDGEMENTS}

Sponsorship for this study, article processing charges, and the Open Access fee were funded by Janssen Scientific Affairs, LLC.

Medical writing support was provided by Qisu Zhang, MPH of STATinMED Research. Support for this assistance was funded by Janssen Scientific Affairs, LLC.
All named authors meet the International Committee of Medical Journal Editors (ICMJE) criteria for authorship for this manuscript, take responsibility for the integrity of the work as a whole, and give final approval to the version to be published.

Disclosures. M. Ingham is an employee of Janssen Scientific Affairs, LLC, which funded the study. M. Ingham is also a stockholder in Johnson \& Johnson, the parent company of Janssen Scientific Affairs, LLC, and manufacturer of Remicade (infliximab) and Simponi (golimumab). A. Teeple is an employee of Janssen Scientific Affairs, LLC, which funded the study. A. Teeple is also a stockholder in Johnson \& Johnson, the parent company of Janssen Scientific Affairs, LLC, and manufacturer of Remicade (infliximab) and Simponi (golimumab). All parties participated in the study design. L. Xie is an employee of STATinMED Research-paid consultants to Janssen Scientific Affairs, LLC-and participated in the analysis and interpretation of the data as well as the writing of the manuscript. $\mathrm{H}$. Tan is an employee of STATinMED Research-paid consultants to Janssen Scientific Affairs, LLC-and participated in the analysis and interpretation of the data as well as the writing of the manuscript. M.F. Kariburyo is an employee of STATinMED Research-paid consultants to Janssen Scientific Affairs, LLC-and participated in the analysis and interpretation of the data as well as the writing of the manuscript. Janssen Scientific Affairs, LLC also participated in the interpretation of the data and the writing of the manuscript.

Compliance with Ethics Guidelines. This article is based on previously conducted studies and does not involve any new studies of human or animal subjects performed by any of the authors. This study was approved by Sterling IRB as an expedited review.

Data Availability. The datasets during and/ or analyzed during the current study are available from the corresponding author on reasonable request. 
Open Access. This article is distributed under the terms of the Creative Commons Attribution-NonCommercial 4.0 International License (http://creativecommons.org/licenses/ by-nc/4.0/), which permits any noncommercial use, distribution, and reproduction in any medium, provided you give appropriate credit to the original author(s) and the source, provide a link to the Creative Commons license, and indicate if changes were made.

\section{REFERENCES}

1. Korzenik JR, Podolsky DK. Evolving knowledge and therapy of inflammatory bowel disease. Nat Rev Drug Discov. 2006;5(3):197-209.

2. Burisch J, Munkholm P. The epidemiology of inflammatory bowel disease. Scand J Gastroenterol. 2015;50(8):942-51.

3. Molodecky NA, Soon SI, Rabi DM, et al. Increasing incidence and prevalence of the inflammatory bowel diseases with time, based on systematic review. 2012;142(1):46.e42-54.e42. Gastroenterology.

4. Levesque BG, Sandborn WJ, Ruel J, Feagan BG, Sands BE, Colombel JF. Converging goals of treatment of inflammatory bowel disease from clinical trials and practice. Gastroenterology. 2015;148(1):37.e1-51.e1.

5. Ford AC, Sandborn WJ, Khan KJ, Hanauer SB, Talley NJ, Moayyedi P. Efficacy of biological therapies in inflammatory bowel disease: systematic review and meta-analysis. Am J Gastroenterol. 2011;106(4):644-59.

6. Sewitch MJ, Abrahamowicz M, Bitton A, et al. Psychosocial correlates of patient-physician discordance in inflammatory bowel disease. Am J Gastroenterol. 2002;97(9):2174-83.

7. Rubin DT, Siegel CA, Kane SV. Impact of ulcerative colitis from patients' and physicians' perspectives: results from the UC: NORMAL survey. Inflamm Bowel Dis. 2009;15(4):581-8.

8. Westwood N, Travis SP. Review article: what do patients with inflammatory bowel disease want for their clinical management? Aliment Pharmacol Ther. 2008;27(Suppl 1):1-8.

9. Siegel CA. Review article: explaining risks of inflammatory bowel disease therapy to patients. Aliment Pharmacol Ther. 2011;33(1):23-32.
10. Zolnierek KB, Dimatteo MR. Physician communication and patient adherence to treatment: a meta-analysis. Med Care. 2009;47(8):826-34.

11. Stewart MA. Effective physician-patient communication and health outcomes: a review. CMAJ. 1995;152(9):1423-33.

12. Charles C, Gafni A, Whelan T. Decision-making in the physician-patient encounter: revisiting the shared treatment decision-making model. Soc Sci Med. 1999;49(5):651-61.

13. Sewitch MJ, Abrahamowicz M, Dobkin PL, Tamblyn R. Measuring differences between patients' and physicians' health perceptions: the patient-physician discordance scale. J Behav Med. 2003;26(3):245-64.

14. Bolge SC, Brown D, Goren A, Meyer R, Ginsberg S. Openness to and preference for biologic therapy among patients with rheumatoid arthritis prior to biologic initiation: patient and prescriber perspectives. Paper presented at Arthritis and Rheumatism 2013; October 2013; San Diego, CA.

15. Charlson M, Szatrowski TP, Peterson J, Gold J. Validation of a combined comorbidity index. J Clin Epidemiol. 1994;47(11):1245-51.

16. de Groot V, Beckerman H, Lankhorst GJ, Bouter LM. How to measure comorbidity: a critical review of available methods. J Clin Epidemiol. 2003;56(3):221-9.

17. Deyo RA, Cherkin DC, Ciol MA. Adapting a clinical comorbidity index for use with ICD-9-CM administrative databases. J Clin Epidemiol. 1992;45(6):613-9.

18. Cohen J. A power primer. Psychol Bull. 1992;112(1):155-9.

19. Siegel CA. Shared decision making in inflammatory bowel disease: helping patients understand the tradeoffs between treatment options. Gut. 2012;61(3):459-65.

20. Siegel CA. Making therapeutic decisions in IBD: the role of patients. Curr Opin Gastroenterol. 2009;25(4):334.

21. O'Connor AM, Wennberg JE, Legare F, et al. Toward the 'tipping point': decision aids and informed patient choice. Health Aff (Millwood). 2007;26(3):716-25.

22. Charles C, Gafni A, Whelan T. Shared decision-making in the medical encounter: what does it mean? (or it takes at least two to tango). Soc Sci Med. 1997;44(5):681-92.

23. Levinson W, Kao A, Kuby A, Thisted RA. Not all patients want to participate in decision making. A national study of public preferences. J Gen Intern Med. 2005;20(6):531-5. 